\title{
Development of brewing science in (and since) the late 19th century: molecular profiles of 110-130 year old beers
}

Walther, Andrea; Ravasio, Davide; Qin, Fen; Wendland, Jurgen; Meier, Sebastian

Published in:

Food Chemistry

Link to article, DOI:

10.1016/j.foodchem.2015.03.051

Publication date:

2015

Document Version

Peer reviewed version

Link back to DTU Orbit

Citation (APA):

Walther, A., Ravasio, D., Qin, F., Wendland, J., \& Meier, S. (2015). Development of brewing science in (and since) the late 19th century: molecular profiles of 110-130 year old beers. Food Chemistry, 183, 227-234. https://doi.org/10.1016/j.foodchem.2015.03.051

\section{General rights}

Copyright and moral rights for the publications made accessible in the public portal are retained by the authors and/or other copyright owners and it is a condition of accessing publications that users recognise and abide by the legal requirements associated with these rights.

- Users may download and print one copy of any publication from the public portal for the purpose of private study or research.

- You may not further distribute the material or use it for any profit-making activity or commercial gain

- You may freely distribute the URL identifying the publication in the public portal 
1 Development of brewing science in (and since) the late $19^{\text {th }}$

2 century: molecular profiles of 110-130 year old beers

3

$4 \quad$ Andrea Walther, ${ }^{1}$ Davide Ravasio, ${ }^{1}$ Fen Qin,,${ }^{1}$ Jürgen Wendland ${ }^{1}$ and Sebastian

$\operatorname{Meier}^{1,2^{*}}$

6

7

8

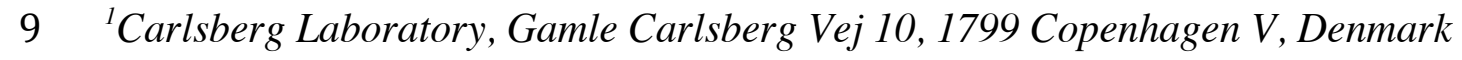
10

$11{ }^{2}$ Department of Chemistry, Technical University of Denmark, Kemitorvet, Building

12 201, DK-2800 Kgs. Lyngby

13 * Correspondence to Sebastian Meier, Technical University of Denmark, Kemitorvet,

14 Building 201,DK-2800 Kgs.Lyngby, E-mail: semei@kemi.dtu.dk

15

16 Keywords: aging; historic samples; molecular archaeology; NMR; oligosaccharides 
19 The $19^{\text {th }}$ century witnessed many advances in scientific enzymology and 20 microbiology that laid the foundations for modern biotechnological industries. In

21 the current study, we analyse the content of original lager beer samples from the 22 1880s, 1890s and 1900s with emphasis on the carbohydrate content and 23 composition. The historic samples include the oldest samples brewed with pure 24 Saccharomyces carlsbergensis yeast strains. While no detailed record of beer 25 pasteurization at the time is available, historic samples indicate a gradual 26 improvement of bottled beer handling from the 1880 s to the 1900 s, with 27 decreasing contamination by enzymatic and microbial activities over this time 28 span. Samples are sufficiently well preserved to allow comparisons to present29 day references, thus yielding molecular signatures of the effects of $20^{\text {th }}$ century 30 science on beer production. Opposite to rather stable carbohydrate profiles, 31 some aldehydes reach up to $\mathbf{4 0 - f o l d ~ h i g h e r ~ l e v e l s ~ i n ~ t h e ~ h i s t o r i c ~ s a m p l e s ~ a s ~}$ compared to present-day references. 


\section{Introduction}

37 The emergence of human societies is closely linked to the onset of agriculture, use of 38 controlled fireplaces, domestication of plants and craftsmanship for producing pottery 39 or metal kettles. These factors have been prerequisites for the production of beer and 40 other fermented beverages with analgesic, disinfectant and mind-altering effects 41 (McGovern, Zhang, Tang, Zhang, Hall, Moreau, et al., 2004; Meussdoerffer, 2009; 42 Walther, Hesselbart, \& Wendland, 2014). In providing nutritive clean products, 43 whose consumption was a social act, fermented beverages themselves have 44 supposedly impacted strongly on the development of human societies (Libkind, 45 Hittinger, Valerio, Goncalves, Dover, Johnston, et al., 2011). The emergence of a 46 barley-based forerunner of modern beer dates at least to the time of $6000 \mathrm{BC}$. The 47 molecular archaeology of beer samples has recently attracted interest in the recovery 48 of a malt- and hop-containing beverage from a schooner that is believed to have sunk 49 in the $1840 \mathrm{~s}$ in the Aland archipelago southwest of Finland (Wilhelmson, 50 Londesborouhg, \& Juvonen, 2012). These samples with acidic pH and almost entirely 51 degraded maltooligosaccharides due to bacterial infections date back to the time 52 before the advent of pasteurization or pure brewing yeast cultures. Degraded samples 53 permit only limited conclusions about what kind of beer originally was filled into the 54 bottles.

Several advances in technology and knowledge mark the onset of scientific 56 brewing towards the end of the $19^{\text {th }}$ century. Industrial-scale brewing had rapidly 57 emerged during the industrial revolution. In particular the popularity of cold58 fermented lager beers from the middle of the $19^{\text {th }}$ century posed new challenges in the 59 cooling of brewing equipment and for yeast handling, however. Following the 
60

61

62

development of scientific enzymology and microbiology, it became evident in 1860 that yeast fermentation converts sugar into ethanol and $\mathrm{CO}_{2}$ (Sicard \& Legras, 2011). The problem of contamination by wild spoilage yeasts was aggravated by the introduction of summertime lager beer fermentation. In 1883, Emil Christian Hansen isolated pure cultures of Saccharomyces strains at the Carlsberg Laboratory. One of these strains, Unterhefe No. 1, was chosen as production strain at the Carlsberg brewery due to its convincing brewing performance, donated to other breweries and entered the CBS strain collection as Saccharomyces carlsbergensis (Walther, Hesselbart, \& Wendland, 2014).

Samples dating back to the development of scientific brewing towards the end of the $19^{\text {th }}$ century could play a role in clarifying, how products and processes evolved during this time and how advances in the brewing process have altered the final product, lager beer, compared to its 19th century ancestors. In order to address these questions, three beer bottles filled with original lager beer from the late 19th century and early $20^{\text {th }}$ century (Figure 1A) were obtained from the Carlsberg Museum bottle collection. More specifically, the three bottles can be dated to the 1880 s or 1890 s for bottle 1 , the 1890 s for bottle 2 and the 1900s for bottle 3 . The extent of bottled beer pasteurization at the time has not been determined. Yeast cells were found in the cell slurries present in bottle 1, and Unterhefe No. 1 was isolated (Walther, Hesselbart, \& Wendland, 2014).

Here, the content of the bottles was subjected to detailed analysis with a special emphasis on barley carbohydrates and aging markers. Complex changes in the chemical composition of beer during storage constitute a well-known problem even during normal shelf-life. Carbonyl compounds such as those deriving from Strecker degradation, Maillard reactions and fatty acid oxidation are of particular importance 
Schutter, Delvaux, \& Delvaux, 2008; Vanderhaegen, Neven, Verachtert, \&

Derdelinckx, 2006). Despite of their volatility, acyclic, aromatic and heterocyclic aldehyde markers formed by Strecker and Maillard reactions during beer aging were detected in historic samples at levels up to 40-fold of a present-day reference sample using gas chromatography.

Carbohydrates are the main carbon substrate of the fermentation process and polysaccharide fragments in the product are informative on production conditions and raw material usage (Marcone, Wang, Albabish, Nie, Somnarain, \& Hill, 2013). Using high-resolution nuclear magnetic resonance (NMR) spectroscopy, all samples were found to contain significant quantities of carbohydrates, including fermentable sugars, even after up to 130 years. Various unconventional carbohydrate signals that are less abundant in present-day samples may be attributed to aging or to the use of $19^{\text {th }}$ century cereal varieties. Despite a limited sample set of unique historical bottles, the carbohydrate profiles indicate a gradual improvement of beer handling from the $1880 \mathrm{~s}$ to the 1900 s and provide a reference to visualize the improved usage of raw materials due to $20^{\text {th }}$ century biotechnology.

\section{Materials and methods}

\subsection{Samples}

106 Three dark brown glass bottles sealed with a cork and metal ring were obtained from 107 the Carlsberg Museum bottle collection filled with original lager beer from the late 108 19th century and early $20^{\text {th }}$ century. The bottles were present as unique copies, and 109 were chosen as the oldest samples with entirely intact bottle glass as well as cork seals 
110 and metal rings, thus indicating that the original material was contained in the bottles.

111 The times where the fillers named on the bottle labels were licensed for bottling were

112 used to date the bottles. All bottles were sprayed and washed extensively with ethanol

$113(70 \% \mathrm{v} / \mathrm{v})$, opened in a clean bench and the bottle content was removed by pipetting

114 with sterile pipettes rather than by pouring. All three historic samples were

115 characterized with a DMA35 handheld density meter, while limitations in sample

116 amount allowed only beer sample 2 to be characterized with an Alcolyzer Beer

117 Analyzing System (Anton Paar, Graz, Austria). The liquid of the bottles was directly

118 frozen at $-20{ }^{\circ} \mathrm{C}$. The bottom slurry was used for the re-isolation of cells. For

119 comparison, a modern lager beer was used. Glucose, maltose, maltotriose,

120 maltotetraose, maltopentaose and maltohexaose reference compounds for HPLC were

121 obtained from Sigma-Aldrich (St. Louis, MO, USA), Dextra Laboratories (Reading,

122 UK) or Carbosynth (Compton, UK). Ethyl-glucoside was produced in situ as a

123 reference compound for alcoholic glucosides using glucose $(20 \mathrm{mg} / \mathrm{ml})$, ethanol (20

$124 \mathrm{mg} / \mathrm{ml}$ ) and 100 units of Bacillus stearothermophilis $\alpha$-glucosidase (E.C. 3.2.1.20,

125 Megazyme, Bray, Ireland). The spectral positions of the ethyl- $\alpha$-D-glucoside were

126 determined without product purification using ${ }^{1} \mathrm{H}-{ }^{13} \mathrm{C}$ NMR spectroscopy.

\subsection{Spectroscopy}

129 NMR spectroscopy was applied as a robust, quantitative and non-destructive approach

130 for the detection of various organic molecule classes without the need for sample 131 derivatization or purification. Of the three historic and one reference (modern) lager 132 beer samples, $500 \mu \mathrm{l}$ were mixed $1: 1$ with $\mathrm{D}_{2} \mathrm{O}$ containing $20 \%(\mathrm{v} / \mathrm{v}) \mathrm{d}_{3}$-acetic acid

133 (Sigma-Aldrich, St. Louis, MO, USA) in order to acquire $1 \mathrm{D}{ }^{1} \mathrm{H}$ NMR spectra 134 including volatile compounds directly after the opening of the bottles (Nord, Vaag, \& 
135 Duus, 2004). The residual $\mathrm{d}_{2}$-acetic acid signal of all samples was used for $1 \mathrm{D}{ }^{1} \mathrm{H}$ 136 NMR spectral normalization. The 1D proton spectra of Figure 1B, C were acquired by 137 sampling 16384 complex data points during an acquisition time of 1.57 seconds and a 138 recycle delay of 10 seconds using excitation sculpting for water suppression, while 139 the 2D DQF-COSY spectrum was recorded with water suppression by presaturation 140 as a data matrix of $4096 \times 512$ complex data points sampling 0.85 and 0.11 seconds in 141 the direct and indirect dimensions, respectively. Ethanol content was measured by 142 integration relative to an alcohol free reference sample spiked with $4 \mathrm{mg} / \mathrm{ml}$ ethanol 143 and mixed 1:1 with $\mathrm{D}_{2} \mathrm{O}$ containing $20 \%(\mathrm{v} / \mathrm{v}) \mathrm{d}_{3}$-acetic acid.

144 For ${ }^{1} \mathrm{H}-{ }^{13} \mathrm{C}$ NMR spectroscopy, $1.5 \mathrm{ml}$ of the beer samples were lyophilized 145 and redissolved in phosphate buffer (100 mM ,pH 6.5) in $\mathrm{D}_{2} \mathrm{O}$ (99.9\%; Cambridge 146 Isotope Laboratories, Andover, MA, USA). The strong buffer was used to stabilize 147 the $\mathrm{pH}$ and thus the signal positions of ionizable analytes. All NMR spectra were 148 recorded at $298 \mathrm{~K}$ on an $800 \mathrm{MHz}$ Bruker (Fällanden, Switzerland) DRX 149 spectrometer equipped with a TCI CryoProbe and an 18.7 T magnet (Oxford Magnet 150 Technology, Oxford, UK) using conventional linear data sampling. ${ }^{1} \mathrm{H}-{ }^{13} \mathrm{C}$ HSQC 151 spectra were recorded with a spectral sweep width of $30 \mathrm{ppm}(6027.86 \mathrm{~Hz})$ around a $152{ }^{13} \mathrm{C}$ offset of $95.0 \mathrm{ppm}$. All spectra employed hard excitation and refocusing pulses, 153 only. Spectra were processed with extensive zero filling and shifted sine bell window 154 function in both dimensions. Data were processed in Topspin 2.1 (Bruker, Fällanden, $155 \mathrm{CH})$. All spectra were referenced relative to residual glucose with $\delta^{1} \mathrm{H}_{1}=5.229 \mathrm{ppm}$ 156 and $\delta^{13} C_{1}=92.99$ ppm for $\alpha$-glucopyranose (Petersen, Hindsgaul, \& Meier, 2014). 
159 Fluorescence labeling with 2-aminobenzamide prior to hydrophobic interaction liquid 160 chromatography (HILIC) analysis on a UPLC (Waters) was performed on reference 161 standards and beer as follows (Bøjstrup, Petersen, Beeren, Hindsgaul, \& Meier, 2013; 162 Hughes \& Johnson, 1982). Glucose, maltose, maltotriose, maltotetraose, 163 maltopentaose and maltohexaose were dissolved in water to concentrations of 1 $164 \mathrm{mg} / \mathrm{ml} .100 \mu \mathrm{l}$ of these solutions were lyophilized. $100 \mu \mathrm{l}$ of each beer sample were 165 lyophilized. To these lyophilized samples was added $100 \mu \mathrm{l}$ of a 1 M solution of 2166 aminobenzamide in $\mathrm{DMSO} / \mathrm{AcOH}(7: 3)$, followed by adding $100 \mu \mathrm{l}$ of a $1 \mathrm{M}$ solution 167 of $\mathrm{NaBH}_{3} \mathrm{CN}$ in $\mathrm{DMSO} / \mathrm{AcOH}$ (7:3). Samples were whirlmixed and incubated for 4 168 hours at $60{ }^{\circ} \mathrm{C}$, then cooled to room temperature and diluted (1:400) with a mixture of $16910 \mathrm{mM}$ ammonium formate buffer $(\mathrm{pH} 4.5)$ and acetonitrile (22:78). Samples were 170 centrifuged and directly analyzed. Of the labeled samples, $5 \mu$ were injected into 171 Waters Acquity UPLC System equipped with Acquity glycan column, FLR detector 172 (excitation wavelength of $350 \mathrm{~nm}$ and emission wavelength of $420 \mathrm{~nm}$ ) using an 173 Acquity UPLC BEH glycan $1.7 \mu \mathrm{m}, 2.1 \times 150 \mathrm{~mm}$ column with a VanGuard BEH 174 glycan $1.7 \mu \mathrm{m}, 2.1 \times 5 \mathrm{~mm}$ pre-column at room temperature.

\subsection{Solid-phase microextraction and chromatography}

177 Aldehydes and other volatile compounds were extracted using solid-phase 178 microextraction prior to detection and quantification by gas chromatographic 179 separation coupled to mass spectrometric analysis (GC-MS) with a Thermo Scientific 180 Quantum GC triple quadropole mass spectrometer. As an internal standard, 2-octanol 181 was added to each sample. Samples $(2.5 \mathrm{ml})$ were prepared in $20 \mathrm{ml}$ vials by adding 182 appropriate amounts of sodium chloride (final concentration $40 \mathrm{mg} / \mathrm{ml}$ ), $50 \mu \mathrm{l} \mathrm{NaN} \mathrm{N}_{3}$ $183(0.1 \% \mathrm{w} / \mathrm{v}), 25 \mu \mathrm{l}$ 2-octanol (final concentration of $200 \mu \mathrm{g} / \mathrm{l}$ ) and ascorbic acid (to a 
final concentration of $20 \mathrm{mg} / \mathrm{ml}$ ). All samples were incubated for $10 \mathrm{~min}$ at $50{ }^{\circ} \mathrm{C}$.

185 Solid-phase microextraction was performed using a 186 divinylbenzene/carboxen/polydimethylsiloxane fiber (DVB-CAR-PDMS) for an 187 extraction time of $40 \mathrm{~min}$. A solgel-wax GC column $(30 \mathrm{~m} / \mathrm{i} . \mathrm{d}$. $0.25 \mathrm{~mm} / \mathrm{Film} 0.25$ $188 \mu \mathrm{m})$ was used for all analyses. Helium gas was used as the carrier with a gas flow rate 189 of $1.2 \mathrm{ml} / \mathrm{min}$. The thermal desorption time of analytes was $4 \mathrm{~min}$. The MS detector 190 was operated in full scan mode at $70 \mathrm{eV}$ with a scan range from 35 to $350 \mathrm{~m} / \mathrm{z}$. Data 191 were analysed using the ThermoXcalibur software (Version 2.2 SP1.48, Thermo 192 scientific) and compound identification based on the NIST version 2.0 mass spectral 193 database.

\section{Results}

\subsection{D NMR spectra of old beer samples}

198 High-resolution nuclear magnetic resonance spectroscopy is an established method 199 for the compositional analysis of non-fractionated beer samples (Duarte, Barros, 200 Almeida, Spraul, \& Gil, 2004; Duarte, Godejohann, Braumann, Spraul, \& Gil, 2003; 201 D. Lachenmeier, Frank, Humpfer, Schäfer, Keller, Mörtter, et al., 2005). The complex 202 constitution of carbohydrates in beer has been addressed using NMR spectroscopy of 203 non-fractionated beer samples only rather recently (Beeren, Petersen, Bojstrup, 204 Hindsgaul, \& Meier, 2013; Bøjstrup, Petersen, Beeren, Hindsgaul, \& Meier, 2013; 205 Petersen, Hindsgaul, \& Meier, 2014; Petersen, Motawie, Moller, Hindsgaul, \& Meier, 206 2014; Petersen, Nilsson, Bojstrup, Hindsgaul, \& Meier, 2014). Challenges in the 207 NMR analysis of carbohydrates relate to the narrow ${ }^{1} \mathrm{H}$ chemical shift range, 208 congestion with the water signal and the vast constitutional complexity (including 
varying branching, ring sizes and anomeric configurations) of carbohydrates (Laine,

210 1994). Figure 1B displays ${ }^{1} \mathrm{H}$ NMR spectra of the historic beer samples designated

211 bottle 1 , bottle 2 and bottle 3 (bottle 3 being the youngest sample at 110 years of age)

212 in comparison to a present-day lager beer. Carbohydrates are observed at considerable 213 amounts in all samples, whereas starch fragments ( $\alpha$-glucans) remain the main 214 constituents of samples above 100 years of age.

215 A noteworthy trend is observed for samples bottle 1, bottle 2 and bottle 3 in

216 the spectra of Figure 1B, where newer beers contain more $\alpha(1-4)$-glucan signals $\left({ }^{1} \mathrm{H}\right.$

217 chemical shifts of 5.3-5.5 ppm), while older beers contain less $\alpha(1-4)$-glucan signal

218 but more reducing end signals $\left({ }^{1} \mathrm{H}\right.$ chemical shifts around $\left.5.23 \mathrm{ppm}\right)$. The spectral 219 signature of $\alpha(1-6)$-branch points on the other hand is nearly identical in all historic 220 samples, but is different in present-day lager, which displays more extensive cleavage 221 of amylopectin towards the non-reducing end of branch points. While limit dextrins 222 appear to be stable in the historic samples, maltooligosaccharides apparently have 223 been degraded to smaller sugars, presumably after bottling, especially in the historic 224 beer bottle 1 . Such activity in the bottled beer is consistent with the purification of 225 living Unterhefe yeast cells from the historic bottle 1. Specifically, the beer sample 226 from bottle 3 shows $\alpha$-reducing end signals with an integral of $8 \%$ of the $\alpha(1-4)$ 227 glucan signal and $\alpha(1-6)$ glucan signals with an integral of $14 \%$ of the $\alpha(1-4)$-glucan 228 signals, as compared to $14 \% \alpha$-reducing end and $16 \% \alpha(1-6)$ glucan signals for bottle 2292 , and $17 \% \alpha$-reducing end and $24 \% \alpha(1-6)$ glucan signals for bottle 1 due to a loss of 230 intact $\alpha(1-4)$-glycosidic bonds in the older bottles. As compared to a present day 231 reference with $12 \% \alpha$-reducing end and $23 \% \alpha(1-6)$ glucan signals relative to $\alpha(1-$ 232 4)-glucan signals, bottle 3 contains significantly more intact $\alpha(1-4)$-glycosidic bonds. 
234 aliphatic and aromatic spectral regions of ${ }^{1} \mathrm{H}$ NMR spectra (Figures 1C, D). The

235 ethanol contents were $2.9 \%, 4.8 \%$ and $2.8 \%$ for samples of bottles 1, 2 and 3, 236 respectively. Historic samples showed classical amino acid and organic acid profiles 237 of beers. All historic samples had higher organic acid content than a present-day 238 reference, particularly more formate, lactate and acetate. The $\mathrm{pH}$ values of samples 239 from bottles 1, 2 and 3 were 4.95, 4.4 and 4.3, respectively, and thus comparable to 240 present-day beers. In comparison, values for bacterially degraded historic samples 241 from the 1840s were as low as pH 3 (Wilhelmson, Londesborouhg, \& Juvonen, 242 2012). The higher $\mathrm{pH}$ of the beer from bottle 1 , above the $\mathrm{pKa}$ of acetate, could 243 explain the survival of yeast cells, supposedly in a dormant state, for 130 years in this 244 particular bottle. Yeast cells clearly are not dormant due to the lack of a fermentable 245 carbon source in bottle 1 (Figure 1B), but presumably due to the lack of other 246 nutrients. The apparent extract was determined with a handheld density meter to 1.8 , 2472.3 and $4.9 \%$ for samples of bottles 1,2 and 3, respectively. In addition, the sample of 248 bottle 2 was characterized on an Alcolyzer Beer Analyzing System to yield an EBC 249 color value of $54.8 \%, 3,59 \%$ real extract, $61,52 \%$ real degree of fermentation and $2502,3 \%$ apparent extract.

\subsection{Maltooligosaccharide quantitation}

253 The varying abundance and degradation of maltooligosaccharides in the beer samples 254 was probed by hydrophobic interaction liquid chromatography (HILIC) after the 255 fluorescence labeling of beer samples. Chromatograms of Figure 2 support the ${ }^{1} \mathrm{H}$ 256 NMR spectroscopic finding of maltooligosaccharide degradation to small fermentable 257 sugars, specifically glucose, especially in bottle 1, but lesser so in bottle 2 and 
especially bottle 3 .

259 Due to its stability, the beer in bottle 3 thus still gives a reasonable clue of

260 carbohydrate composition and content in lager beers from the beginning of the $20^{\text {th }}$

261 century. Maltotriose levels in bottle $3(3.16 \mathrm{mg} / \mathrm{ml})$ were more than 4-fold higher than

262 in a present-day reference $(0.71 \mathrm{mg} / \mathrm{ml})$, while maltotetraose was the most abundant 263 maltooligosaccharide in bottle $3(3.9 \mathrm{mg} / \mathrm{ml})$ and the present-day sample, albeit half

264 the concentration in the present-day sample $(2.02 \mathrm{mg} / \mathrm{ml})$ (Table 1). Not surprisingly

265 then, modern brewing methods have considerably improved the efficiency of raw 266 material usage. Notwithstanding, the HILIC traces of historic and present-day beers 267 show similar patterns of additional signals other than maltooligosaccharides. Thus, 268 variations in the composition of the most abundant sugars other than 269 maltooligosaccharides are limited, consistent with the similar profiles of limit dextrins 270 detected in ${ }^{1} \mathrm{H}$ NMR spectra.

\subsection{D NMR-chemical detail of carbohydrate composition}

273 Highly resolved signatures of carbohydrate composition in the beer samples were 274 sought using homo- and heteronuclear 2D NMR spectroscopy. Figure 3A,B shows the 275 2D NMR detection of barley cell-wall carbohydrates, specifically arabinoxylan and $\beta$ 276 glucan in the historic beer samples. The beer of bottle 1 is largely devoid of 277 arabinoxylan and $\beta$-glucan, consistent with the action of microbial and/or enzymatic 278 activities in the bottle. Beers of bottles 2 and 3 contain arabinoxylan and $\beta$-glucan 279 signals that indicate a poor cleavage of these polysaccharides in beer production at the 280 turn of the last century, consistent with the fact that arabinoxylan and $\beta$-glucan pose 281 challenges for beer filterability throughout the $20^{\text {th }}$ century and even today ( $\mathrm{Li}, \mathrm{Lu}$, 282 Gu, Shi, \& Mao, 2005). 
284 in modern-style samples, or at considerably lower levels. Hence, the chemical 285 composition of carbohydrates and carbohydrate-adducts may be a possible aging 286 marker or may reflect the change in cereal varieties and malting practices since the $28719^{\text {th }}$ century (Ferrio, Alonso, Voltas, \& Araus, 2006; D. W. Lachenmeier \& Fügel, 288 2007; Linko, Haikara, Ritala, \& Penttilä, 1998). Figures 3C and 4A indicate that 289 especially beer from bottle 1 contains glucans linked to primary alcohols that do not 290 derive from starch fragments $(\sim 4.93 \mathrm{ppm}$, at slightly lower frequency than the limit 291 dextrin $\alpha(1-6)$ branch points). Signal frequencies and sharp line widths indicate that 292 these signals arise from glucosides formed between $\alpha$-anomeric glucose and low 293 molecular weight alcohols, for instance ethanol and glycerol. As the chemical 294 glycoside formation is acid catalyzed, while the beer from bottle 1 has the highest $\mathrm{pH}$ 295 of the historic beer samples, the formation of glucosides with low molecular weight 296 alcohols may result from enzymatic processes involving $\alpha$-glucosidase instead. Such 297 an enzymatic, and hence specific mechanism, also seems plausible considering the 298 absence of corresponding $\beta$-glucosides in the spectral vicinity of gentiobiose (6-O- $\beta$ 299 D-glucopyranosyl-D-glucose, i.e. a glucopyranosyl $\beta$-linked to a primary alcohol 300 group at glucose C6, Figure 4B). Figure 4B indicates some further differences in 301 mono- and disaccharide composition of the beer samples and underlines the closest 302 resemblance of present-day lager beer by the beer of bottle 3, albeit with little 303 degradation of arabinoxylan to xylose and xylobiose fragments.

\subsection{Aging markers}

306 Beyond probing historical production conditions, the old beer samples were used to 307 validate and approximate limiting values of selected aging markers. The historic beer 
samples were analysed using gas chromatographic separation coupled to mass spectrometric analysis (GC-MS). Several volatile compounds, for instance acetate esters (ethylacetate, isoamylacetate, phenylethyacetate), showed strongly reduced

311 abundance, down to less than $1 \%$ of present-day reference values. The decline of 312 these esters over more than a century could result from their high volatility and 313 presumably does not allow simple conclusions about the flavor profile of beer at the 314 onset of brewing science. In contrast, several aging markers (Vanderhaegen, Neven, 315 Verachtert, \& Derdelinckx, 2006) were analysed, including Strecker aldehydes 316 (benzaldehyde, 3-methylbutanal) and Maillard aldehydes (furfural and 5317 methylfurfural), showing 3-fold to 40-fold higher values than in the present-day 318 reference (Table 2). Thus, these mentioned aldehydes in historic beer samples were 319 well suited to observe chemical reactivity during beer storage and were validated as 320 suitable aging markers. A comprehensive list of compounds analyzed by solid-phase 321 microextraction and GC-MS is provided in the supplemental Table S1.

\section{Discussion}

325 The use of pure culture lager yeast strains by Emil Christian Hansen revolutionized 326 lager beer production in the outgoing $19^{\text {th }}$ century (Hansen, 1883). This first lager 327 beer yeast strain is known as Saccharomyces carlsbergensis, originally termed 328 Unterhefe No 1, and has been used in production since 1883 (Walther, Hesselbart, \& 329 Wendland, 2014). Here, we analyse the molecular profiles of historic lager beer 330 samples intact beer bottles filled in the 1880 s, 1890 s and 1900 s in comparison to 331 present-day references in order (1) to retrace the biotechnological challenges and 332 shortcomings in raw material handling at the onset of scientific brewing and (2) to 
333 probe chemical, enzymatic and microbial reactivities during beer aging on historic 334 timescales.

335 The enzymatic remodeling of carbohydrates in complex mixtures is a hallmark 336 of many biotechnological production processes, including brewing. The carbohydrate 337 composition in the historic beer samples indicates an improved stability of the bottled 338 product from the 1880 s to the 1900 s. This finding is consistent with a growing 339 awareness of the importance of keeping wine and beer germ free following the work 340 of Pasteur in the 1860s and 1870s (Stewart \& Russell, 1986). Two-dimensional NMR 341 spectroscopy shows that enzymatic activities in the supposedly oldest beer bottle have 342 led to the predominant degradation of maltooligosaccharides as well as barley 343 arabinoxylan and mixed linkage $(1,3-1,4) \beta$-glucan. Such degradation decreases in the 344 beer samples from the 1890 s to the 1900 s. The youngest historic beer sample from the 345 early 1900s contains most of its maltooligosaccharides in form of maltotriose and 346 maltotetraose and thus reflects the composition of present-day lager beers. The good 347 preservation of starch fragments in historic samples uniquely allows the comparison 348 with present-day samples and the identification of unconventional carbohydrates as 349 possible products of historic cereal varieties. For instance, maltotriose and 350 maltotetraose occur in the historic lager beer sample from the early 1900s at levels 2351 4-fold higher than for typical present-day lager beers (see literature averages in Table 352 1), thus reflecting the push towards optimized processes in present-day brewing. The 353 analysis of 10 recent lager beer samples of different years and sites from major 354 breweries (Table 1) revealed that all the present day samples had lower levels of 355 maltotriose and maltotetraose present in the historic lager beer sample from the early 356 1900s. This sample from the early 1900s has the lowest $\mathrm{pH}$ (4.2) and highest organic 357 acid content (Figure 1C) of the historic samples, while containing the least degraded 
oligosaccharides and lowest monosaccharide concentrations. Hence, the

359 oligosaccharides can be considered chemically stable under weakly acidic conditions 360 in aqueous medium for more than a century.

361 Opposite to linear oligosaccharides, branched limit dextrins are found in all

362 historic beer samples at similar levels, and are evidently more resistant to amylase 363 degradation than maltooligosaccharides (Beeren, Petersen, Bojstrup, Hindsgaul, \& 364 Meier, 2013). The limit dextrin structures in the historic samples are larger than those 365 found in present-day lager beer, again consistent with the improved usage of raw 366 materials in present-day lager beers, owing to the improved control over enzyme367 dependent processes during the course of the $20^{\text {th }}$ century. When not degraded in 368 historic samples, the viscous cell wall polysaccharides arabinoxylan and mixed 369 linkage $(1,3-1,4) \beta$-glucan occur as large fragments rather than oligosaccharides, in 370 agreement with viscosity and filterability problems associated with these cell wall 371 polysaccharides throughout the $20^{\text {th }}$ century and until today. The detection of living, dormant Saccharomyces carlsbergensis yeast cells 373 and large amounts of alcoholic $\alpha$-glycosides in the supposedly oldest sample is 374 consistent with the presence of enzymatic activities after bottling. In addition, 375 Sporobolomyces roseus (a beer spoilage yeast that is else not present in our lab) was 376 detected in the same bottle 1. Determinations of the yeast species were based on 377 rDNA sequencing. The presence of dormant yeast cells of 130 years of age in this 378 sample may be favored by the only weakly acid sample $\mathrm{pH}(\mathrm{pH} 4.9)$. Yeast dormancy 379 in this sample occurs despite the presence of glucose above concentrations of $2 \mathrm{~g} / \mathrm{l}$, 380 presumably as the consequence of cytostasis due to nitrogen starvation, ethanol or 381 acidic $\mathrm{pH}$. Sporobolomyces could have survived as spores, while $S$. carlsbergensis as 382 a triploid yeast has no tendency to sporulate. The use of polymerase chain reaction 
validates the presence of $S$. carlsbergensis DNA in the sample (Walther, Hesselbart, $384 \&$ Wendland, 2014).

Various carbohydrate signals are observed in historic beer samples that are

386 absent from the present-day reference. Due to their low concentration and the absence

387 of suitable reference compounds, these additional carbohydrate signals remain

388 hitherto unassigned. Markers of beer aging were determined in historic and present-

389 day samples in order to estimate the changes in beer chemical composition beyond

390 carbohydrates on historic timescales. Using gas chromatographic analysis, we find

391 that several volatile compounds are reduced to less than $1 \%$ of present-day reference

392 values. In contrast, several aging markers including Strecker aldehydes and

393 heterocycles showed 3-40-fold higher values than in the present-day reference.

394 In concluding, we analyse lager beer samples bottled shortly after the advent

395 of scientific brewing, including some of the first brews using pure lager yeast culture.

396 Historic beer samples contain most of the carbohydrates that are found in present-day

397 beer. Historic samples reflect an improving control over enzymatic polysaccharide 398 degradation processes at the end of the $19^{\text {th }}$ century, yielding samples that are stable to 399 chemical, enzymatic and microbial degradation for more than a century. In constrast, 400 severe changes in chemical composition are found for esters and aldehydes. These 401 finding underline the stability of carbohydrate profiles and their utility in molecular 402 archaeology.

\section{Acknowledgements}

405 We thank Bjarne Maurer for providing access to the Carlsberg bottle collection and 406 insight into exact dating of bottles based on the respective labels used. This work was 407 funded by grant 2010_01_0135 of the Carlsberg Foundation to J.W.. S.M. 
408 acknowledges Jens Duus and grant 2013_01_0709 of the Carlsberg Foundation for 409 funding.

\section{Conflict of interest statement}

411 The authors declare no conflicts of interest.

412 


\section{References}

Beeren, S. R., Petersen, B. O., Bojstrup, M., Hindsgaul, O., \& Meier, S. (2013). Timeresolved in-situ observation of starch polysaccharide degradation pathways. Chembiochem, 14(18), 2506-2511.

Bøjstrup, M., Petersen, B. O., Beeren, S. R., Hindsgaul, O., \& Meier, S. (2013). Fast and accurate quantitation of glucans in complex mixtures by optimized heteronuclear NMR spectroscopy. Anal Chem, 85(18), 8802-8808.

Duarte, I. F., Barros, A., Almeida, C., Spraul, M., \& Gil, A. M. (2004). Multivariate Analysis of NMR and FTIR Data as a Potential Tool for the Quality Control of Beer. Journal of Agricultural and Food Chemistry, 52(5), 1031-1038.

Duarte, I. F., Godejohann, M., Braumann, U., Spraul, M., \& Gil, A. M. (2003). Application of NMR Spectroscopy and LC-NMR/MS to the Identification of Carbohydrates in Beer. Journal of Agricultural and Food Chemistry, 51(17), 4847-4852.

Ferreira, I. M. P. L. V. O. (2009). Beer Carbohydrates. Beer in Health and Disease Prevention, Preedy, V.R.(Associated press Burlington, MA, USA).

Ferrio, J. P., Alonso, N., Voltas, J., \& Araus, J. L. (2006). Grain weight changes over time in ancient cereal crops: Potential roles of climate and genetic improvement. Journal of Cereal Science, 44(3), 323-332.

Hansen, E. C. (1883). Recherches sur la physiologie et la morphologie des ferments alcooliques V. Methodes pour obtenir des cultures pures de Saccharomyces et de mikroorganismes analogues. . C. R. Trav. Lab. Carlsberg, 2, 92-105.

Hughes, S., \& Johnson, D. C. (1982). High-performance liquid chromatographic separation with triple-pulse amperometric detection of carbohydrates in beverages. Journal of Agricultural and Food Chemistry, 30(4), 712-714.

Lachenmeier, D., Frank, W., Humpfer, E., Schäfer, H., Keller, S., Mörtter, M., \& Spraul, M. (2005). Quality control of beer using high-resolution nuclear magnetic resonance spectroscopy and multivariate analysis. European Food Research and Technology, 220(2), 215-221.

Lachenmeier, D. W., \& Fügel, D. (2007). Reduction of Nitrosamines in Beer Review of a Success Story. BrewingScience, 60, 84-89.

Laine, R. A. (1994). Invited Commentary: A calculation of all possible oligosaccharide isomers both branched and linear yields $1.05 \times 1012$ structures for a reducing hexasaccharide: the Isomer Barrier to development of single-method saccharide sequencing or synthesis systems. Glycobiology, 4(6), 759-767.

Li, Y., Lu, J., Gu, G., Shi, Z., \& Mao, Z. (2005). Studies on water-extractable arabinoxylans during malting and brewing. Food Chem, 93(1), 33-38.

Libkind, D., Hittinger, C. T., Valerio, E., Goncalves, C., Dover, J., Johnston, M., Goncalves, P., \& Sampaio, J. P. (2011). Microbe domestication and the identification of the wild genetic stock of lager-brewing yeast. Proc Natl Acad Sci U S A, 108(35), 14539-14544.

Linko, M., Haikara, A., Ritala, A., \& Penttilä, M. (1998). Recent advances in the malting and brewing industry1. Journal of Biotechnology, 65(2-3), 85-98. 
Marcone, M. F., Wang, S., Albabish, W., Nie, S., Somnarain, D., \& Hill, A. (2013). Diverse food-based applications of nuclear magnetic resonance (NMR) technology. Food Research International, 51(2), 729-747.

McGovern, P. E., Zhang, J., Tang, J., Zhang, Z., Hall, G. R., Moreau, R. A., Nunez, A., Butrym, E. D., Richards, M. P., Wang, C. S., Cheng, G., Zhao, Z., \& Wang, C. (2004). Fermented beverages of pre- and proto-historic China. Proc Natl Acad Sci U S A, 101(51), 17593-17598.

Meussdoerffer, F. G. (2009). A Comprehensive History of Beer Brewing. In Handbook of Brewing, (pp. 1-42): Wiley-VCH Verlag GmbH \& Co. KGaA.

Nord, L. I., Vaag, P., \& Duus, J. O. (2004). Quantification of organic and amino acids in beer by 1H NMR spectroscopy. Anal Chem, 76(16), 4790-4798.

Petersen, B. O., Hindsgaul, O., \& Meier, S. (2014). Profiling of carbohydrate mixtures at unprecedented resolution using high-precision $1 \mathrm{H}-13 \mathrm{C}$ chemical shift measurements and a reference library. Analyst, 139(2), 401-406.

Petersen, B. O., Motawie, M. S., Moller, B. L., Hindsgaul, O., \& Meier, S. (2014). NMR characterization of chemically synthesized branched alpha-dextrin model compounds. Carbohydr Res.

Petersen, B. O., Nilsson, M., Bojstrup, M., Hindsgaul, O., \& Meier, S. (2014). (1)H NMR spectroscopy for profiling complex carbohydrate mixtures in nonfractionated beer. Food Chem, 150, 65-72.

Rodrigues, J. A., Barros, A. S., Carvalho, B., Brandão, T., \& Gil, A. M. (2011). Probing beer aging chemistry by nuclear magnetic resonance and multivariate analysis. Analytica Chimica Acta, 702(2), 178-187.

Saison, D., De Schutter, D. P., Delvaux, F., \& Delvaux, F. R. (2008). Optimisation of a complete method for the analysis of volatiles involved in the flavour stability of beer by solid-phase microextraction in combination with gas chromatography and mass spectrometry. Journal of Chromatography $A$, 1190(1-2), 342-349.

Sicard, D., \& Legras, J.-L. (2011). Bread, beer and wine: Yeast domestication in the Saccharomyces sensu stricto complex. Comptes Rendus Biologies, 334(3), 229-236.

Stewart, G. G., \& Russell, I. (1986). One hundred years of yeast research and development in the brewing industry. Journal of the Institute of Brewing, 92(6), 537-558.

Vanderhaegen, B., Neven, H., Verachtert, H., \& Derdelinckx, G. (2006). The chemistry of beer aging - a critical review. Food Chem, 95(3), 357-381.

Walther, A., Hesselbart, A., \& Wendland, J. (2014). Genome sequence of Saccharomyces carlsbergensis, the world's first pure culture lager yeast. G3 (Bethesda), 4(5), 783-793.

Wilhelmson, A., Londesborouhg, J., \& Juvonen, R. (2012). Analysing the shipwreck beer. http://www.vtt.fi/files/news/2012/Hylkyolut_Maarianhamina_1005201 2_Wilhelmson.pdf. 
506 Figure 1. (A) Historic bottles from the Carlsberg Museum bottle collection filled with 507 original lager beer. Time ranges for their filling were deduced from the names of 508 fillers given on the labels. (B) ${ }^{1} \mathrm{H}$ NMR spectrum of the spectral region containing $\alpha-$ 509 anomeric sugar signals from starch fragments in the present-day reference and historic 510 beer samples of the bottles shown in (A). The hump at $5.35 \mathrm{ppm}$ results from $\alpha(1-4)$ 511 signals near branch points. Horizontal lines designate $\alpha-(1 \rightarrow 4)$ glycosidic bonds, vertical 512 lines designate $\alpha-(1 \rightarrow 6)$ glycosidic bonds and circles designate glucopyranosyl units, where 513 the filled circle yields the signal in a structural motif indicated by open circles. (C) ${ }^{1} \mathrm{H}$ NMR 514 spectrum of the aliphatic spectral region. Increased organic acid content, especially of 515 lactate and acetate, is evident, while amino acids content does not appear significantly

516 increased. Residual $\mathrm{d}_{2}$-acetate signal derives from addition of $\mathrm{d}_{3}$-acetate for stabilizing 517 sample $\mathrm{pH}$ and internal referencing. (D) ${ }^{1} \mathrm{H}$ NMR spectrum of the aromatic spectral 518 region, showing increasing formic acid content in historic samples 1-3 and the 519 absence of broad protein background signals in the historic samples due to protein 520 hydrolysis or precipitation. The ${ }^{1} \mathrm{H}$ NMR spectra are normalized relative to an internal 521 residual d2-acetate standard signal.

523 Figure 2. HILIC traces of 2-aminobenzamide labeled beer samples for the 524 quantitation of glucose, maltose and maltooligosaccharides in historic samples and a 525 present-day reference. Absolute quantitations were derived using a mixture of 526 standard compounds. Quantitations are tabulated in Table 1. G1-G6 represent $\alpha(1-4)$ 527 linked glucans with dp 1 (glucose) to dp 6 (maltohexaose). 
529 Figure 3. (A) ${ }^{1} \mathrm{H}-{ }^{1} \mathrm{H}-\mathrm{COSY}$ and (B) ${ }^{1} \mathrm{H}-{ }^{13} \mathrm{C}$ HSQC spectra of barley cell wall 530 polysaccharides in the historic beer samples. The spectra indicate nearly complete 531 degradation in bottle 1 , presumably after bottling, and intact $\beta$-glucopyranosyl (red) 532 and $\beta$-xylopyranosyl (orange) polysaccharide chains with little chain cleavage in 533 beers from bottles 2 and 3. In depictions of arabinoxylan fragments, squares designate 534 arabinofuranosyl units, circles designate xylopyranosyl-units, horizontal lines indicate $535 \beta-(1 \rightarrow 4)$ glycosidic bonds, vertical lines indicate $\alpha-(1 \rightarrow 2)$ glycosidic bonds, and 536 diagonal lines indicate $\alpha-(1 \rightarrow 3)$ glycosidic bonds. In depiction of $\beta$-glucan structures, 537 circles designate glucopyranosyl units, horizontal lines indicate $\beta-(1 \rightarrow 4)$ glycosidic 538 and diagonal lines indicate $\beta-(1 \rightarrow 3)$ glycosidic bonds. (C) Presence of alcoholic $\alpha$ 539 glycosides in beer from bottle 1 at ${ }^{1} \mathrm{H}-{ }^{13} \mathrm{C}$ HSQC spectral positions indicated by 540 arrows. Ethyl- $\alpha$-glucopyranoside was identified using an enzymatically synthesized 541 reference compound.

543 Figure 4. (A) ${ }^{1} \mathrm{H}^{-13} \mathrm{C}$ HSQC spectra of historic and present-day lager beer samples.

544 Spectral regions corresponding to starch fragments are highlighted in bottle 1 and 545 regions corresponding to $\beta$-glucan and $\beta$-xylan for sample bottle 2 . Additional signals 546 that are not present in present-day lager samples, or at lesser amounts, are highlighted 547 by a grey area in sample bottle 3. (B) Spectral region highlighting differences in 548 mono- and disaccharide compositions of historic and present-day lager beer samples. 
552 Table 1. Glucose and maltooligosaccharide content of historic beer samples in $\mathrm{g} / \mathrm{l}$.

\begin{tabular}{|c|c|c|c|c|c|c|}
\hline Sample & Glucose & Maltose & Maltotriose & $\begin{array}{l}\text { Malto- } \\
\text { tetraose }\end{array}$ & $\begin{array}{c}\text { Malto- } \\
\text { pentaose }\end{array}$ & $\begin{array}{l}\text { Malto- } \\
\text { hexaose }\end{array}$ \\
\hline Bottle 1 & 2.54 & 0.13 & 0.04 & 0.05 & nd & nd \\
\hline Bottle 2 & 1.86 & 1.48 & 2.03 & 0.33 & nd & 0.04 \\
\hline Bottle 3 & 0.36 & 0.70 & 3.16 & 3.90 & 0.80 & 0.41 \\
\hline ref & 0.02 & 0.39 & 0.71 & 2.02 & 0.33 & nd \\
\hline ref $a^{a}{ }^{a}$ & $0.07 \pm 0.03$ & $0.15 \pm 0.26$ & $0.46 \pm 0.36$ & $1.51 \pm 0.60$ & $0.39 \pm 0.20$ & $0.19 \pm 0.08$ \\
\hline lit $\mathbf{a v} \mathbf{v}^{\mathbf{b}}$ & nd & $0.05 \pm 0.10$ & $1.25 \pm 0.71$ & $3.45 \pm 1.31$ & nd & nd \\
\hline
\end{tabular}

554 pulsed amperometric detection (as described in (Bøjstrup, Petersen, Beeren, 555 Hindsgaul, \& Meier, 2013)) of 10 contemporary commercial lager beer samples of 556 major brewing companies. The analysis includes samples of the years 2011-2014,

557 including sample variation from different sites.

558 baverage determination by HPLC analyses of 18 lager beers reported in the literature 559 (Ferreira, 2009). 
561 Table 2. Strecker aldehydes and heterocyclic aldehydes produced during beer aging,

562 reported as parts per billion (w/v) as determined by GC-MS analysis.

\begin{tabular}{ccccc}
\hline Sample & Furfural & $\begin{array}{c}\text { 5-Methyl } \\
\text { furfural }\end{array}$ & Benzaldehyde & $\begin{array}{c}\text { 3-Methyl } \\
\text { butanal }\end{array}$ \\
\hline Bottle 1 & 70.38 & 7.76 & 30.17 & 7.72 \\
Bottle 2 & 143.91 & 10.74 & 138.91 & 9.83 \\
Bottle 3 & 401.69 & 18.91 & 26.89 & 5.14 \\
ref & 14.44 & 0.56 & 10.87 & nd \\
\hline
\end{tabular}

563 